\title{
Sehu: Dalang Wayang Potehi (布袋戲) di Jawa
}

\author{
Hirwan Kuardhani \\ Jurusan Teater FSP Institut Seni Indonesia Yogyakarta \\ Email: kuardhani@gmail.com
}

\begin{abstract}
Potehi is a hand-glove puppetry theatre art form, brought by the Chinese emigrant from Fujian in the sixteenth century. It used to be performed in their vessels (JungJung) when they were docked. The Hokkian dialect was used at that time. As more Chinese immigrants settled down in Indonesia, they carried along the Potehi art in Java. Along the way, Potehi ceased to be performed in Hokkien dialect. Instead, it was Melayu Pasar or Melayu rendah (now Indonesian Language) being used, which was indeed the lingua franca among the Chinese community then. Nevertheless songs and poetry were still in Hokkian. Sehu called dalang Potehi. Was originally sehu as Hokkian true, a long the way sehu as Pranakan's Tionghoa an than in this time sehu from etnic Java. The acculturation with the local society resulted in a very unique Potehi which was different from its original version.
\end{abstract}

Keywords: puppetry of Potehi in Java; sehu; acculturation

\begin{abstract}
Abstrak
Potehi merupakan pertunjukan sarung tangan, yang dibawa para emigran China dari Fujian sekitar abad enam belas. Potehi biasanya dipertunjukkan di Jung-jung atau kapal-kapal mereka ketika sedang mendarat. Mereka menggunakan bahasa Hokkian dalam pertunjukannya. Ketika orang-orang Tionghoa menetap di Indonesia mereka membawa serta kesenian Potehi di Jawa. Pada perkembangannya pementasan Potehi tidak lagi menggunakan bahasa Hokkian melainkan menggunakan bahasa Melayu Pasar atau Melayu Rendah (sekarang bahasa Indonesia), bahasa yang sekaligus menjadi bahasa pengantar kaum Tionghoa saat itu. Walaupun untuk lagu dan syair masih memakai bahasa Hokkian. Sehu merupakan sebutan bagi dalang wayang Potehi. Awalnya sehu adalah orang Hokkian asli, pada perkembangannya adalah orang-orang Peranakan, dan saat ini sehu dari etnis Jawa. Proses akulturasi dengan penduduk setempat membuat pertunjukan Potehi menjadi unik dan berbeda dengan negeri asalnya.
\end{abstract}

Kata kunci: wayang Potehi di Jawa; sehu; akulturasi

\section{Pendahuluan}

Pertunjukan wayang di Jawa sudah ada sejak abad IX. Hal ini dibuktikan oleh adanya istilah "haringgit" dalam Prasasti Kuti 840 M. Padanan kata "haringgit" adalah "awayang" dijumpai dalam Prasasti Tajigunung $910 \mathrm{M}$, dan sampai sekarang kata ringgit dan wayang masih digunakan (Haryono, 2008: 34). Teater boneka Potehi (布袋戲) di Jawa disebut sebagai wayang Cina dan berasal dari Provinsi Fujian (福建) tepatnya di daerah Quanzhou dan Zhangzhou. Selain di dua daerah itu, banyak juga dimainkan di Propinsi Guangdong (广东). Kapan awal kedatangannya di Pulau Jawa 
ada dugaan sekitar abad XVI seperti diungkap oleh Timbul Haryono (2008: 46) sebagai berikut:

"Naskah sastra banyak menyebut tentang pertunjukan wayang. Bahkan menarikuntuk disinggung adalah tentang Wayang Cina. Istilah tersebut muncul dalam naskah yang lebih muda seperti Malat dan Nawaruci. Di dalam Nawaruci misalnya dikatakan "anggambuh, amancangah, alalangkaran mwang awayang Cina". Di dalam Malat disebutkan: "amancangah, anggringgit Cina”. Hal tersebut menunjukkan bahwa wayang Cina sudah masuk ke Jawa sekitar abad XVI atau XVII".

Wayang Cina yang dimaksud di sini diduga kuat adalah Potehi karena bentuk-bentuk teater boneka jenis lainnya dari Tiongkok tidak ditemukan bekas-bekasnya. Boneka dari kulit, seperti wayang Purwa, atau jenis bertali (marrionet), maupun jenis bertangkai tidak dikenal masyarakat Jawa, kebanyakan dari mereka mengenal wayang Cina adalah Potehi. Hal ini dikuatkan dengan data bahwa kebanyakan emigran Tiongkok yang datang ke Jawa adalah orang-orang Hokkian (Fujian) yang merupakan pemilik pertunjukan Potehi. Wayang Potehi merupakan pertunjukan yang dipakai untuk keperluan ritual para emigran Tionghoa dari Hokkian/Fujian (福建) sekaligus merupakan alat hiburan bagi para emigran tersebut. Potehi biasanya dipertunjukkan di Jung-jung atau kapalkapal mereka ketika sedang mendarat di pesisir utara Jawa. Mereka menggunakan bahasa Hokkian dalam pertunjukannya.

Pada abad ke-17 pertunjukan boneka Potehi sudah populer di kota Batavia dan daerah lain. Shu Ming dalam artikelnya Yajiada Zaoqi Kaifa Yu Huaren (Pengembangan Jakarta di Masa Awal dan Masyarakat Tionghoa) mengatakan dalam pertunjukan Potehi di kota Batavia (Jakarta) dalam perkenalan jalan cerita dan dialog Potehi, serta lakon-lakon Tiongkok Selatan lainnya yang dipentaskan pada pertemuan hari raya atau pekan kelenteng di Jakarta telah diterjemahkan dalam bahasa setempat. Bahasa setempat yang dimaksud adalah dialek Melayu Jakarta, untuk memenuhi kebutuhan warga peranakan dan pribumi yang tidak paham bahasa Tionghoa atau dialek Tiongkok (Mulyono, 1982: 13 dan 117).
Para emigran Tiongkok yang berasal dari wilayah Hokkian tidak hanya para pekerja biasa seperti petani, peternak, perajin, pedagang atau nelayan melainkan banyak yang memang berprofesi sebagai sehu sebutan bagi dalang pertunjukan Potehi. Di Kecamatan Gudo-Jombang keturunan Sehu Tok Su Kwie mengisahkan bahwa sang kakek merupakan sehu (dalang) pertunjukan Potehi dari Hokkian yang datang ke Jawa bersama rombongan pemain musiknya berjumlah delapan orang. Ia membawa pula seluruh perlengkapan teater boneka Potehi dari Tiongkok (Wawancara dengan Tok Hok Lay tanggal 10 Maret 2010). Para pemusik anggota Sehu Tok Su Kwie jika tidak sedang mengiringi pertunjukan, mereka bekerja sebagai peternak babi, pedagang, pengrajin tahu, dan lain sebagainya, apapun yang dapat dijadikan sumber penghidupan, sedangkan sang sehu hanya mendalang tidak melakukan pekerjaan lainnya. Di saat tidak mendalang biasanya seorang sehu membuat boneka Potehi, mereparasi yang rusak, membuat baju boneka dan sebagainya.

Dalang wayang Potehi disebut sehu. Ia merupakan pemain sentral dalam pertunjukan Potehi. Dalam proses pementasan Potehi, sehu dibantu oleh seorang asisten sehu dan para pemain musik. Sejak kedatangan Potehi di Jawa hingga saat ini, sehu dapat dikelompokkan menjadi tiga kelompok yakni: (1) sehu yang datang dari Tiongkok dan masih berbahasa Tiongkok dialek Hokkian (Tionghoa totok), (2) sehu Tionghoa Peranakan (Tionghoa keturunan yang lahir di Jawa), dan (3) sehu dari etnis Jawa.

\section{Para Sehu Emigran dari Hokkian}

Pada masa lalu para sehu masih berbahasa Hokkian dalam mendalang Potehi, karena ratarata mereka merupakan emigran Tionghoa dari Hokkian. Pertunjukan Potehi merupakan bagian dari ritual upacara persembahan bagi dewa. Pertunjukan Potehi bahkan diduga pula merupakan bagian upacara pengusiran roh jahat seperti ditulis oleh Groenendael (1993: 18):

"in Java too in the past there may possibly have been a link between Potehi and exorcism as has been suggested by Poensensarticle. I have no conclusive evidence of more recent exorcistical practices, however". 
Dari kutipan tersebut terlihat bahwa seorang sehu memiliki kedudukan penting. Selain mendalang, sehu merupakan perantara dunia kasat mata dengan dunia roh. Ia menjadi pemuka dalam "bargaining" dengan para roh jahat agar mereka tidak mengganggu kehidupan sehari-hari manusia (dalam hal ini komunitas Tionghoa). Sehu yang berasal dari Hokkian masih mampu mementaskan lakon "Pendeta mengusir Roh dari Altar Hitam" untuk upacara membersihkan suatu tempat, pindah rumah, dan sebagainya, yang diyakini tempat-tempat tersebut ada "penunggunya".

Di samping upacara pengusiran roh jahat, sehu pun mendalang untuk perayaan-perayaan kelentheng seperti Ulang tahun Kelentheng, Hari Raya Persembahan Arwah, Hari Raya Imlek, Cap Go Meh, dan sebagainya. Dapat dikatakan bahwa seorang sehu merupakan "perantara" bagi "kesejahteraan" yang diinginkan masyarakat pendukungnya. "Kesejahteraan" di sini bukan berarti "kekayaan”, namun "kesejahteraan' yang dimaksud merupakan keseimbangan antara lahir dan batin dalam pemenuhan kebutuhan sesuai kaidahkaidah budaya masyarakat Tionghoa. Di dalam melakukan tugasnya seorang sehu harus menguasai mantra-mantra pengusir roh jahat, pun doa-doa yang menentramkan. Biasanya mantra dan doa-doa diambil dari ajaran-ajaran Tao, Kong $\mathrm{Hu} \mathrm{Cu}$ atau Budha. Pentas Potehi dalam rangka persembahan bagi dewa tidak saja harus menyenangkan hati para dewa agar umat selalu dilindungi dari marabahaya berupa apapun, namun sekaligus untuk mempertebal ketabahan hati agar umat mampu menahan kesukaran-kesukaran dari Thian (Tuhan) yang datang tak terelakan seperti: wabah, bencana alam, dan sebagainya. Sehu sebagai pemimpin pertunjukan wayang Potehi dianggap memiliki "daya Illahi” yang dapat meredam marabahaya.

Lakon-lakon yang dipentaskan para sehu (setelah disetujui dewa) memberikan pedoman dan arah tertentu bagi khalayak penontonnya. Intiinti lakon merupakan perwujudan dari lambanglambang kebaikan dan kejahatan, hidup dan kematian, dosa dan penyucian, perkawinan dan kesuburan, sorga dan neraka. Pendeknya isi lakon lebih padat dari sekedar rangkaian peristiwa yang menghibur.

Sehu harus mampu menghadirkan kembali mitos-mitos leluhur. Mitos dalam hal ini bukan hanya semacam reportase mengenai peristiwaperistiwa yang dulu terjadi, atau kisah mengenai dewa-dewa dan dunia ajaib, tetapi mitos yang dapat memberikan arah kepada perilaku umat dan memberikan pedoman bagi kearifan manusia. Melalui mitos manusia dapat ikut mengambil bagian dalam kejadian-kejadian di sekitarnya, dan dapat menanggapi daya-daya kekuatan alam. Untuk melengkapi mitos-mitos yang dihadirkan melalui lakon-lakon, maka seorang sehu juga melengkapi dengan perwujudan lewat simbol-simbol yang dipahatkan pada panggung pertunjukan Potehi. Pada panggung penuh dengan ukiran dan pahatan yang sarat makna seperti: Delapan Dewa, Bunga Teratai, Kelelawar, kuil, lonceng, dan sebagainya yang kesemuanya merupakan lambang perwujudan dari mitos yang diyakini masyarakat Tionghoa. Lambang-lambang tersebut merupakan jendelajendela yang membuka pandangan terhadap dunia transenden. Sebagaimana dikatakan M. Eliade (dalam Van Peursen, 1988: 42) bahwa lambanglambang menunjukkan ke arah kekuasaan yang ada di atas dan di luar manusia (transenden). Dewadewa pun merupakan lambang-lambang, dalam pementasan dongeng-dongeng mitis, dewa-dewa itu seolah-olah dihadirkan di tengah-tengah umat manusia. Para sehu masa lalu yang datang dari Hokkian sering melakonkan Theogoni yakni kisahkisah para dewa atau terjadinya dewa seperti Poei San (Delapan Dewa), Hongsin Peng, dan sebagainya. Pertunjukan Potehi utamanya dipersembahkan bagi para dewa, namun di samping itu pertunjukan Potehi sekaligus merupakan sarana hiburan bagi umat Kelentheng.

Seorang sehu merupakan pemasok penting nilai-nilai budaya, moral, sejarah, sastra, dan banyak aspek dari pendidikan non-formal bagi masyarakat pendukungnya. Dengan memberikan "pendidikan" melalui ajaran-ajaran kebajikan yang diuraikan melalui lakon-lakonnya, seorang sehu merupakan "guru" bagi masyarakat pemilik pertunjukan Potehi. Peran sehu sangat penting bagi komunitas Tionghoa di perantauan, ia tidak saja memimpin pertunjukan bagi kebutuhan ritual, menghibur, memberikan wejangan sekaligus ia merupakan penjaga tradisi leluhur. Para sehu pendatang dari Hokkian antara lain, Nyoo Kim Hwat, Koo Kim Swie, Go Hok Lim, Tok Su Kwie, Gan Coco dan sebagainya. Kostum yang dikenakan sehu emigran Tiongkok 
saat mendalang adalah "baju gunting Cina" atau dikenal sebagai baju Koko, karena baju demikian memang merupakan gaya busana komunitas Tionghoa pendatang saat itu.

\section{Pergeseran Etos Kerja pada Sebu Tionghoa Peranakan dan Sehu Etnis Jawa}

Seiring berjalannya waktu, generasi penerus sehu adalah keturunan peranakan yang lahir di tanah perantauan yakni Jawa, dari hasil perkawinan sehu emigran dari Hokkian yang biasa disebut Tionghoa Totok (singkek) dengan wanita setempat dari etnis Jawa atau Peranakan Tionghoa. Keturunan tersebut tidak lagi seratus persen menggunakan bahasa dialek Hokkian dalam kehidupan sehari-harinya. Hal ini berpengaruh pula dalam pementasan Potehi. Para sehu generasi Peranakan sudah mulai menggunakan bahasa Melayu Rendah sebagai bahasa pentas Potehi, meskipun pada adegan penting dan nyanyian masih digunakan bahasa Hokkian. Sebagaimana dikutip oleh Brandon (2003: 73-74) bahwa:

“...Dalam Potehi cerita-cerita Cina dipertunjukkan dengan boneka-boneka berbusana Cina tetapi bahasa yang diucapkan boneka-boneka adalah bahasa Indonesia. Cukup ironis, di antara banyak bentuk seni pertunjukan Indonesia, bahasa Indonesia sebagai bahasa nasional hanya dipergunakan pada Potehi yang berasal dari Cina. Dua puluh sampai dua puluh lima rombongan wayang Potehi beroperasi di Jawa. Mereka hidup di Surabaya dan Semarang, dua kota terbesar di Pulau Jawa yang ada komunitas Cina yang besar. Rombongan-rombongan ini terutama mengadakan pergelaran untuk perayaan-perayaan ulang tahun kuil Budha. Mereka tidak pernah mengadakan pertunjukan di gedung pertunjukan umum dan juga tidak untuk peristiwa-peristiwa pribadi..."

Terjadi peralihan dari periode lama yaitu era sehu yang memakai bahasa Hokkian ke arah periode baru dengan penggunaan bahasa Melayu Rendah. Penggunaan bahasa Melayu Rendah yang kemudian berkembang menjadi bahasa Indonesia, disebabkan para penontonnya tidak hanya para
Tionghoa suku Hokkian tetapi juga dari suku-suku lain seperti Hopek, Teuwciu, Hakka dan sebagainya yang tersebar pula di Jawa meskipun komunitas mereka tidak sebanyak suku Hokkian. Terdapat pula para penonton dari penduduk setempat yakni orang Jawa. Para penonton yang berlainan suku tersebut tidak paham bahasa Hokkian karena itu dipakailah bahasa Melayu Rendah sebagai pengantarnya.

Terjadi pula pergeseran sikap. Para sehu tidak hanya menyajikan pertunjukan di dalam kelentheng dan terkait dengan upacara ritual keagamaan, namun beberapa sehu ada yang mulai mementaskan Potehi sebagai hiburan untuk masyarakat luas. Hal ini dapat dicermati dari kutipan pada bagian depan bahwa pada masa orde lama dan sebelumnya, banyak dijumpai rombongan-rombongan Potehi di kota-kota besar seperti Jakarta, Surabaya, Semarang, yang berpentas di berbagai tempat seperti: terminal, pasar malam, dan tempat keramaian lannya. Di Pasar Malam Sekatenan Yogyakarta, sebuah teater kecil didirikan khusus untuk pertunjukan Potehi. Pada tahun 1963 di kota Semarang orang mudah menemukan sebuah panggung Potehi diletakkan di atas sebuah gerobak sapi sehingga para pemain dapat membawa panggung tersebut tanpa harus membongkar dan memasang jika berpindah tempat pentas.

Pertunjukan Potehi tidak hanya dilakukan di dalam kelentheng yang terkait dengan ritual keagamaan, namun sudah mulai merambah pentas untuk hiburan di luar kelentheng. Hal tersebut diduga bahwa para sehu mulai dihadapkan pada persoalan ekonomi, di mana imbalan mendalang dari kelentheng tidak lagi mencukupi kebutuhan hidup sehari-hari para sehu beserta keluarganya. Di saat tidak mendalang nyaris tidak ada pemasukan apapun secara finansial, sementara untuk bekerja di luar mendalang Potehi, para sehu tidak memiliki ketrampilan lain. Mendalang di luar kelentheng kemudian dilakukan oleh para sehu untuk memenuhi kebutuhan hidupnya. Namun demikian tidak semua sehu melakukannya. Sebagai contoh mendiang Sehu Tok Hong Ki di saat tidak mendalang memilih memperbaiki boneka. Sehu Gunawan mengisi waktu kosong dengan membuat boneka. Bagi sehu seperti mereka itu, mendalang di kelentheng merupakan panggilan hidup dan kewajiban. Para sehu Tionghoa Peranakan semua- 
nya beragama Kong $\mathrm{Hu} \mathrm{Cu}$ (Tridarma), sehingga mendalang untuk kelentheng tetap utama karena merupakan ibadah, meskipun dengan imbalan uang yang tidak banyak. Bagi para sehu Tionghoa Peranakan dapat menghibur dewa dan menyenangkan hati para dewa adalah berkah tiada tara. Sisi ibadah dan pengabdian terhadap kelentheng masih sangat diutamakan. Sebagai contoh mendiang Sehu Tok Hong Ki. Ia selalu mendatangi kelentheng yang akan menggelar hajat perayaan kelentheng seperti Imlek, Cap Go Meh, Ulang Tahun Klentheng, San Jit, dan lainlain, serta menawarkan diri untuk mendalang. Ia akan mempresentasikan kebisaannya dalam menyajikan lakon-lakon "berat" mengenai dewadewa (kisah-kisah Theogoni) seperti Delapan Dewa, Hongsin Peng, dan sebagainya. Kedudukan sehu tidak "sekeramat" sehu masa lalu yang datang dari Hokkian, namun keturunannya tetap menguasai kaidah-kaidah pementasan Potehi secara benar termasuk ketika harus mengucapkan narasinarasi dalam lafal Hokkian. Hal ini ditunjang dari kebiasaan mereka dalam berdoa menurut agama Kong $\mathrm{Hu} \mathrm{Cu}$ menggunakan bahasa Tiongkok dialek Hokkian.

Para sehu Tionghoa Peranakan mempelajari lakon-lakon Potehi secara lisan dari guru-guru mereka yakni para sehu pendatang. Di antara para sehu tersebut jarang yang belajar bahasa tulis. Akibat terbatasnya kemampuan menulis dalam tulisan Tiongkok tak jarang para sehu peranakan menuliskan lafal Tiongkok dalam tulisan latin. Jadi hanya bunyi yang dituliskan seperti contoh berikut:

Hong Thian Seng beng Cee Liong Teng, Hong Tiauw Sun Bin an Ling Su Hai Sim Ho Kiong Ciok iok, Bho Thian Thong lok Ging Sing Bing

(Saya duduk sebagai Kaisar

Atas firman Tuhan, karena itu maka

Menjadi Raja haruslah bijaksana

Sehingga empat penjuru raja kecil taat pada perintah

Negara kuat empat penjuru aman sentosa)

Sedangkan untuk jalan cerita jikalau guruguru mereka sudah tiada maka mereka membuat sendiri ringkasan lakon yang akan dipentaskan berdasarkan cerita klasik Tiongkok yang sudah banyak ditulis dan diterbitkan dalam bahasa Melayu
(Indonesia) oleh para penulis Tionghoa Peranakan. Gambar 1 adalah contoh catatan ringkasan lakon.

Tulisan tersebut merupakan tulisan tangan mendiang Sehu Tok Hong Ki ketika membuat ringkasan adegan (Treatment) lakon Hong Sin. Saat ini Sehu Gunawan seorang sehu Tionghoa Peranakan masih menggunakan cara-cara tersebut dalam mendalang. Ia masih memakai catatan yang berisi ringkasan adegan dari lakon yang ia pentaskan.

Pada perkembangannya sehu tidak hanya berasal dari etnis Tionghoa Peranakan, namun mulai muncul para sehu dari etnis Jawa. Anak-anak penduduk setempat dari etnis Jawa yang tinggal di sekitar kelentheng sering menonton pertunjukan Potehi. Bagi mereka pertunjukan teater boneka tersebut sama menariknya dengan wayang kulit Purwa. Di antara anak-anak etnis Jawa tersebut ada yang tertarik mempelajari Potehi seperti misalnya Sehu Sesomo (alm.), Widodo, Sutarto, Purwanto, Sukar Mujiono dan lain-lain. Awalnya mereka senang menonton pertunjukan Potehi, kemudian ketika remaja mereka ikut dalam bermain musik



Gambar 1. Tulisan Sehu Tok Hong Kie meringkas cerita Hongsin dari Cerita Silat bersambung. (Foto repro: Hirwan Kuardhani) 
pengiring Potehi sambil memperhatikan para sehu mendalang. Lambat laun mereka menjadi asisten sehu dan selanjutnya dapat mendalang sendiri.

Gaya mendalang para sehu dari Etnis Jawa berbeda dengan sehu dari etnis Tionghoa Peranakan. Hal ini terjadi karena perbedaan latar budaya masing-masing. Para sehu Tionghoa Peranakan tumbuh dalam budaya Tionghoa dari garis ayah dan mengenal budaya Jawa tempat di mana mereka tinggal. Para sehu dari etnis Jawa tumbuh dalam kultur Jawa dan dekat dengan kesenian wayang kulit. Hal ini sangat mempengaruhi gaya mendalang sehu dari etnis Jawa. Kebanyakan sehu tersebut memiliki referensi pengalaman menonton wayang kulit Jawa, sehingga cara mereka membawakan dialog tercampur gaya mendalang wayang kulit Purwa. Sebagai contoh Sehu Sesomo dari Jombang lagu kalimat yang diucapkan mirip dengan dalang wayang kulit. Meskipun menggunakan bahasa Indonesia tetapi langgam dialognya condong seperti dalang wayang kulit.

Sehu dari etnis Jawa rata-rata beragama Islam, hal ini berpengaruh pada etos mereka. Bagi sehu etnis Jawa mendalang Potehi hanya semata-mata mencari uang, tidak ada unsur ibadah sama sekali. Ketika mereka mendalang di kelentheng-kelentheng dalam rangka ritual keagamaan, seperti memperingati Hari Raya Imlek atau Ulang Tahun kelentheng, mereka melulu bekerja mencari uang dan bisa dikatakan "nunut urip" karena mata pencaharian utama mereka dari mendalang Potehi. Sehu etnis Jawa kurang fasih dalam melantunkan narasi-narasi dalam bahasa Hokkian, sehingga banyak sehu muda dari etnis Jawa yang menghilangkan bagian narasi yang panjang dalam bahasa Hokkian. Para sehu etnis Jawa kurang menguasai lakon-lakon berat tentang dewa-dewa seperti Hongsin, Poe Xian dan sebagainya. Rata-rata sehu etnis Jawa memainkan lakon-lakon yang lebih ringan seperti Sie Jin Kui, Legenda Ular Putih, dan sebagainya. Di samping kurang menguasai lakon-lakon berat dan narasi panjang berbahasa Hokkian, para sehu etnis Jawa kurang menjiwai kedudukannya sebagai sehu yang dulunya punya posisi "keramat" sebagai sehu pertunjukan ritual.

Di dalam menjalankan tugas mendalang, seorang sehu berpakaian bebas, tidak dituntut mengenakan busana khusus sebagaimana dalang wayang kulit di Jawa. Seorang sehu tidak harus mengenakan baju adat Tiongkok. Jika para sehu emigran dari Tiongkok dahulu memang kesehariannya berbusana "Koko", maka sehu Tionghoa Peranakan dan sehu etnis Jawa dapat mengenakan batik, hem, kaos dan sebagainya. Hal ini diduga karena sehu tidak terlihat oleh penonton, ia berada di balik panggung Potehi dan panggung Potehi tersebut dimasukkan di dalam sebuah rumah panggung. Karena tidak tampak dari luar maka ada kebebasan bagi sehu dalam berpakaian. Bahkan ketika cuaca panas, sehu yang berada di dalam rumah panggung berukuran $4 \times 3$ meter dan harus berdesakan dengan sedikitnya lima pemain musik dan satu asisten sehu akan merasa kegerahan. Hal tersebut membuat sehu tidak segan melepas hem luarnya dan hanya memakai singlet.

\section{Pembelajaran bagi Calon Sehu}

Sebagaimana umumnya pertunjukan wayang kulit atau wayang golek di Jawa, Sunda, Bali, Sasak (Lombok), dan sebagainya, dalang adalah penggerak utama pertunjukan. Untuk itu seorang sehu harus memiliki kemampuan komplit sebagai aktor sekaligus sutradara. Kemampuan yang harus dimiliki seorang sehu adalah:

a. Menguasai cerita klasik Tiongkok

Para sehu sebagai pencerita di dalam pentas boneka Potehi diharuskan menguasai ceritacerita klasik Tiongkok. Hal ini penting mengingat di dalam pementasan seorang sehu harus menyodorkan cerita-cerita yang hendak dilakonkan kemudian pihak kelentheng sebagai penanggap akan meminta pada dewa untuk memilih cerita atau lakon yang hendak dimainkan.

b. Memiliki suara merdu enak didengar Suara yang merdu ketika mengutarakan narasi, dialog, monolog dalam mendalang merupakan salah satu daya pikat sebuah pergelaran. Sehu Thio Tiong Gie salah satu sehu bersuara besar (bariton) dalam istilah Jawa "gandem". Sementara banyak sehu dari etnis Jawa kurang bagus suaranya sehingga kurang menarik ketika mendalang. Namun karena terbatasnya jumlah sehu membuat para sehu tersebut masih dipakai hingga kini.

c. Mampu melafalkan kata-kata dalam dialek Hokkian 
Hal ini penting karena banyak narasi, namanama tokoh yang masih dalam bahasa Hokkian. Jika seorang sehu kurang fasih dalam melafalkannya maka pertunjukannya kurang menarik.

d. Memiliki musikalitas yang tinggi dan mampu menyanyi

Sebagai penyampai kisah yang juga akan melantunkan lagu-lagu para sehu dituntut punya suara merdu. Sayangnya disebabkan kurangnya peminat profesi sehu terutama di kalangan Tionghoa Peranakan, maka sehu-sehu yang ada sekarang banyak yang kualitas suaranya pas-pasan. Sementara banyak sehu dari etnis Jawa kurang bagus suaranya untuk bernyanyi, sehingga ada sehu yang jarang menyelipkan nyanyian dalam pergelarannya.

e. Menguasai syair-syair atau pantun Tiongkok Syarat-syarat teknis yang harus dikuasai seorang sehu tentu melalui proses panjang. Proses pembelajaran sebagai sehu dalam memainkan boneka Potehi merupakan tahapan-tahapan yang tidak mudah, terutama bagi sehu dari suku Jawa. Hal ini disebabkan para sehu dari suku Jawa seorang muslim sehingga tidak dekat dengan lakon-lakon seputar Agama Tridarma (Budha, Kong $\mathrm{Hu} \mathrm{Cu}$, Tao) dan referensi mengenai Opera Cina tidak dimiliki sama sekali. Pada perkembangannya sehu Tionghoa Peranakan pun sering mencipta sendiri syair-syair berbahasa Melayu Rendah bahkan berbahasa Jawa. Hal ini merupakan kreativitas para sehu dalam menampilkan kembali pertunjukan Potehi di Jawa.

f. Harus mampu berimprovisasi

Di dalam mendalang Potehi seorang sehu harus mahir berimprovisasi jika terjadi peristiwa khusus. Sebagai contoh ketika Sehu Gunawan tengah mendalang di kuil Kriyan, penulis datang menonton bersama Tok Hok Lay (Toni Harsono) putra mendiang Sehu Tok Hong Kie. Ketika Toni Harsono menyambangi di belakang panggung dan menitipkan oleh-oleh tanda kasih, seketika Sehu Gunawan melakukan improvisasi mendoakan Toni agar senantiasa diberkahi Thian, adegan persembahan dan doa disisipkan tanpa mengganggu lakon.

g. Memiliki kreativitas tinggi

Persebaran pertunjukan teater boneka Potehi di
Jawa sejak awal kedatangannya tidak disertai dengan persebaran Opera Cina baik jenis Opera Kunqu, Opera Peking (Beijing), Opera Huangmei, Opera Yue dan sebagainya. Hal ini diduga disebabkan membawa boneka Potehi lebih ringkas dan praktis, dapat dipentaskan tanpa memakan tempat. Pementasan untuk berbagai kepentingan dari upacara ritual hingga hiburan. Sedangkan Opera membutuhkan pemain yang tidak sedikit, dan jarang ada dari para pendatang Tionghoa yang merupakan aktor-aktor Opera, karena kebanyakan dari para pendatang adalah kaum petani dan pedagang. Hal ini yang membuat para dalang teater boneka Potehi pada perjalanan waktu tidak lagi merujuk pada Opera Cina, baik gaya, lagu, dialog, dan sebagainya. Setelah generasi para sehu Tionghoa totok meninggal, digantikan generasi sehu Tionghoa Peranakan dan sehu suku Jawa, pengenalan terhadap Opera Cina semakin berkurang, bahkan sehu suku Jawa tidak mengenal sama sekali. Ketika bahasa dalam dialog pertunjukan pun memakai bahasa Melayu Rendah pada masa dulu dan memakai bahasa Indonesia pada masa kini, kaitan dengan Opera Cina benar-benar sudah terputus. Hal ini tidak seperti di Tiongkok sendiri atau negara-negara lain seperti Taiwan, Singapura, dan Malaysia di mana Opera Cina masih dipertunjukkan. Di negara asalnya dan negara-negara lain Opera Cina masih merupakan rujukan bagi pembelajaran para dalang Potehi, tetapi di Jawa teater boneka Potehi tumbuh dalam iramanya sendiri, dalam bentuknya yang memiliki perbedaan. Para sehu (dalang) justru memperoleh wawasan dari wayang Jawa seperti wayang kulit dan wayang golek. Bagi mereka yang membedakan adalah cerita yang dimainkan. Kiat-kiat mendalang teater boneka Potehi hampir seperti dalang wayang Jawa sebagaimana dikisahkan oleh Thio Tiong Gie sebagai berikut:

"Menjadi dalang itu harus ngedan. Seorang dalang haruslah ekspresif dan penuh improvisasi saat pentas. Dalang juga harus cerdik memainkan peranannya, mampu menghayati alur cerita sebagai bagian dari dirinya sendiri yang tak dapat dipisahkan. Sehingga keduanya menjadi satu emosi yang sama. Tak mudah menjadi seniman yang berada di tingkat itu. Improvisasi dan gerak- 
gerik akan muncul dan mengalir dengan sendirinya seiring dengan pengalaman mendalang berpuluh-puluh tahun dengan membawakan beberapa lakon yang dipakai sebagai sumber cerita yang berasal dari khazanah sastra Tiongkok klasik".

Secara teknis banyak yang melakukan dengan cara otodidak atau belajar sendiri dengan mencoba terus dan berlatih agar "lanyah" dalam bahasa Jawa yang artinya lancar dan trampil. Seperti yang diungkapkan oleh Thio Tiong Gie seorang dalang senior dari Semarang:

"Ayah saya, Thio Thian Soe dan ibu, Go Giok Nio adalah pedagang kain di kawasan Pecinan, Demak. Toko kami bernama toko kain "Cita". Ketika terjadi kerusuhan besar pada 1942 dan umur saya sembilan tahun, toko kain kami dijarah. Akhirnya kami sekeluarga berhijrah ke Semarang serta sebelumnya kami juga dipenjara karena kerusuhan itu. Kesulitan ekonomi keluarga, memaksa ayah bekerja serabutan. Mulai dari pemulung hingga menjual kue. Ketika umur 25 tahun, saya sedang melipat koran-koran untuk bungkus kue yang dijual ayah saya dan menemukan selembar koran yang berisi tulisan berjudul " $\mathrm{Cu} H u n$ Thay Cu Caw Kong ", sebuah judul cerita pewayangan yang berarti "Putra Mahkota Cu Hun", cerita seorang putra mahkota yang melarikan diri di masa Dinasti Sung. Kisah wayang Potehi itu menyadarkan saya terhadap kecintaan pada budaya. Saya semakin rajin menyaksikan wayang Potehi di Kelenteng Raden, Semarang. Tak lama, saya bertemu dengan Tok Hong Kie, seorang dalang senior dan mengungkapkan ketertarikan pada wayang Potehi. Ia pun menyuruh saya memainkan wayang di Blitar untuk menggantikannya yang saat itu berhalangan tampil. Dalam seminggu, saya belajar menjadi dalang Potehi secara otodidak. Disitulah saya sadar saya memiliki bakat menjadi dalang wayang Potehi hingga sekarang".

Hampir semua sehu (dalang) boneka Potehi belajar secara otodidak atau dengan lebih dahulu nyantrik pada dalang senior. Cara belajar "nyantrik" adalah dengan mengikuti terus pementasan seorang sehu dan biasanya calon sehu menjadi pemusik. Calon sehu saat memegang salah satu alat musik baik erhu, drum, dan sebagainya akan melihat cara sehu mendalang, menyanyikan lagu-lagu, dan membuat harmoni dengan irama musik. Hal ini dimaksudkan untuk mengasah kepekaan calon sehu terhadap musik, karena sehu yang pada awalnya memainkan alat musik akan memiliki kepekaan irama, hal ini sangat membantu ketika memainkan boneka. Sehu pemula biasanya sudah dapat menyanyikan lagu-lagu dalam bahasa Hokkian atau beberapa dalam bahasa Mandarin. Lagu tradisi pun harus dikuasai, mengingat saat berpentas diberbagai event dan tempat terkadang diminta menyanyikan lagu setempat. Sehu pemula akan berlatih memainkan boneka disela-sela waktu pentas. Pentas para sehu setiap hari dan terkadang memakan waktu berbulan-bulan, maka hal ini menguntungkan para calon sehu. Mereka akan berlatih setiap hari. Acapkali sehu utama ada halangan entah sakit atau ada kesibukan mendadak, maka calon sehu akan didaulat menggantikan sehu utama. Saat itulah calon sehu memulai debutnya sebagai sehu utama. Hal ini dialami oleh Thio Tiong Gie, Sesomo, Purwanto, dan lain-lain. Sehu pemula akan beruntung jika sehu seniornya masih bersedia membimbing dirinya sampai layak disebut sehu. Hal lain yang terjadi adalah jika sehu pemula memiliki bakat ketrampilan yang bagus, maka tidak heran jika ada sehu pemula yang lebih trampil dalam memainkan bonekanya, lebih berkualitas dalam membawakan karakter tokoh-tokohnya.

Di Jawa pembelajaran menjadi sehu terlihat sederhana dan alamiah, hampir sama dengan para dalang tradisional wayang kulit ataupun

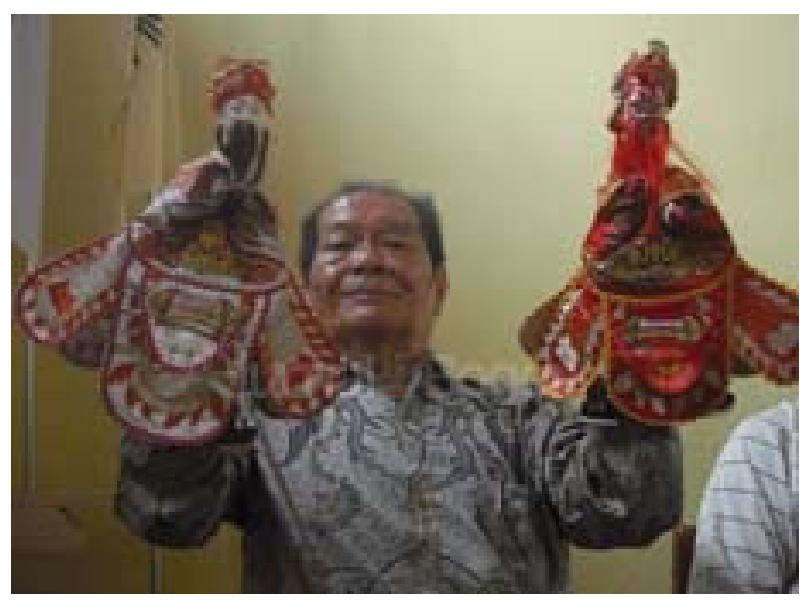

Gambar 2. Teguh Candra Irawan (Tio Thiong Gie) Sehu Potehi, orang Tionghoa. (Foto: Hirwan Kuardhani) 
golek di Jawa. Jika pedalangan Jawa sudah menyelenggarakan pendidikan formal bagi calon dalang seperti Habirandha, Jurusan Pedalangan ISI Yogyakarta, ISI Surakarta, dan sebagainya, maka dalang atau sehu Potehi dalam mengajarkan ketrampilan memainkan boneka Potehi tetap melalui transmisi pedalangan tradisional yakni nyantrik atau dengan cara "tiron" yakni dengan meniru. Hal ini berbeda dengan di Tiongkok, di Taiwan terdapat sekolah formal dalang Potehi. Pemahaman dan pengenalan dengan Opera Cina seperti Kunqu Opera, Beijing Opera, Hokkian Opera, Yue Opera dan lain-lain dilakukan sebagai salah satu sarat pendidikan sehu atau dalang Potehi.

Pelatihan teknik mendalang yang terusmenerus dikembangkan menjadikan perkembangan Potehi berbeda dengan yang terjadi di Jawa. Para sehu di Jawa justru berkembang dalam proses akulturasi dengan budaya setempat dan menampilkan kreativitas yang luar biasa. Wayang kulit Jawa (Wayang Purwa) begitu mempengaruhi para sehu, sehingga membuat antawecana (dialog) dalam pertunjukannya nyaris berlanggam seperti Jawa namun berbahasa Indonesia dan menggunakan nyanyian Hokkian. Terlebih bagi sehu yang setiap tahun rutin mendalang di kelentheng Hong San Kiong saat ulang tahun kelentheng tersebut, pada hari pembukaan perayaan Ulang tahun Kelentheng, pertunjukan Potehi akan disandingkan dengan pertunjukan wayang kulit semalam suntuk. Hal ini sangat mempengaruhi gaya mendalang sehu Potehi seperti yang dialami oleh Sehu Sesomo. Apalagi ketika Sehu Sesomo menikahi seorang pesinden wayang kulit, maka keterpengaruhannya dengan wayang Jawa semakin nyata. Hal ini berpengaruh

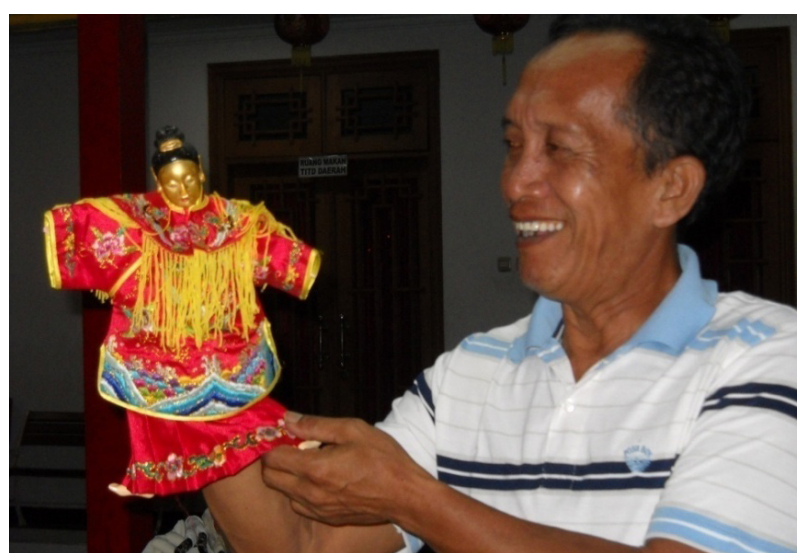

Gambar 3. Sehu Sesomo (alm) orang Jawa mengabdikan seumur hidupnya untuk mendalang wayang Potehi.

(Foto: Naresvara NP) pula dengan sehu-sehu asuhannya seperti Purwanto. Otomatis cara berdialognya akan menuruni gaya Sesomo yang sudah terpengaruh wayang kulit Jawa.

Hal menarik lainnya ialah di Tiongkok, Taiwan atau Hongkong memiliki sekolah formal pedalangan Potehi, di mana di sekolah tersebut diajarkan teknik-teknik mendalang yang terus berkembang. Sedangkan jalur non-formal para calon sehu belajar pada sehu yang lebih senior dengan pola "nyantrik" dengan berbagai "laku" seperti Sehu Yan Feng dan Sehu Yan Seng (dua sehu termayur dari Hokkian). Jikalau di Tiongkok, Taiwan atau Hongkong pendidikan calon sehu ditempuh lewat jalur sekolah formal dan jalur non-formal, tidak demikian di Jawa. Di Jawa terjadi kreativitas cara pembelajaran calon sehu Potehi, yakni dengan memakai sapu tangan yang disimpulkan di semua sudutnya. Simpul tengah pada jari telunjuk mewakili kepala boneka, simpul kiri untuk tangan yang dimainkan oleh ibu jari dan simpul kanan untuk tangan yang diwakili jari tengah.

Kreativitas para sehu terus-menerus dipacu oleh kebutuhan berpentas. Dimulai dari sehuTionghoa Peranakan yang memakai bahasa Melayu Rendah yang untuk seterusnya pertunjukan Potehi di Jawa memakai bahasa Indonesia, memasukkan lagu atau tembang-tembang lokal dalam pertunjukan, atau menerjemahkan lagu-lagu Hokkian dalam bahasa Jawa. Para sehu etnis Jawa sering menyelipkan bahasa Jawa pada adegan-adegan santai untuk mengakrabkan pertunjukan pada penonton seperti misalnya : "...kebo mangan kara, remuk njero gak ketara....", ...tuku bolah kok ijo, jare sekolah kok mbojo..." dan sebagainya. Sehu Sesomo bahkan pernah menggubah lakon berdasarkan komik Cerita Silat bersambung karya Koo Ping Ho. Seperti diketahui karya Koo Ping Hoo bukanlah cerita yang murni mengangkat legenda Tiongkok, melainkan cerita yang dikarang Koo Ping Ho sendiri berlatar belakang Tiongkok. Lakon-lakon yang digubah Sesomo dari Cerita Silat Koo Ping Ho pernah dicoba dipentaskan di kelentheng Hong San Kiong Gudo, Jombang.

\section{Para Sehu yang Tersisa}

Pada masa Orde Lama dan sebelumnya kehidupan teater boneka Potehi di Jawa sangat 
marak. Pertunjukan tersebut merupakan salah satu tontonan menarik bagi masyarakat terutama komunitas Tionghoa Peranakan, meskipun warga pribumi yang lain pun akrab dan gemar dengan tontonan ini. Kemasyuran pertunjukan Potehi tidak disangsikan lagi. Pada setiap perayaan hari raya Tionghoa Potehi dipergelarkan. Acara-acara hajat, kaul, pernikahan, kelahiran dan sebagainya memakai pertunjukan teater boneka Potehi. Hal ini berpengaruh pula pada kehidupan para dalang yang memainkan boneka tersebut. Maraknya pertunjukan menyebabkan banyak pula orangorang yang tertarik untuk menjadi sehu (dalang). Dapat dikatakan pada masa-masa itu jumlah sehu (dalang) teater boneka Potehi cukup memadai.

Ketika Orde Baru berkuasa, kemudian diberlakukan UU pasal 14 tahun 1967, yang berisi pelarangan segala bentuk acara kesenian, ritual, perayaan yang bernuansa Tionghoa maka "tamat" sudah Seni Budaya Tionghoa Peranakan di Indonesia. Hampir segala jenis kesenian bernuansa Tionghoa berhenti pentas di hadapan masyarakat luas. Pertunjukan boleh diadakan hanya di dalam kelentheng dalam rangka perayaan keagamaan, namun tidak diijinkan untuk memakai pengeras suara. Hal ini berlaku pula bagi pertunjukan teater boneka Potehi. Pertunjukan digelar di dalam kelentheng dan hanya ditonton oleh anggota jemaah kelentheng, tanpa pengeras suara, tanpa keriuhan bunyi-bunyian yang biasa mengiringi pertunjukan mereka. Saat ini pelan-pelan keberadaan para sehu ikut menghilang. Banyak dari mereka yang beralih profesi agar tidak berurusan dengan pihak berwajib.

\section{Penutup}

Kehidupan sebagai sehu Potehi memang jauh dari gelimang harta, namun panggilan hidup sebagai sehu tidak akan ditinggalkan meskipun hidup serba kesusahan. Bagi para sehu Tionghoa Peranakan, mereka merasa mengemban amanah leluhur untuk minimal mempertahankan keberadaan pertunjukan wayang Potehi. Bagi sehu asli Jawa yang beragama Islam mendalang wayang Potehi merupakan profesi yang menghasilkan uang untuk penghidupan mereka. Hal tersebut membuat mereka ikut "nguri-uri" keberlangsungan hidup pertunjukan wayang Potehi.

Pada era sekarang ini, pertunjukan Potehi mulai marak dan bangkit kembali, tidak hanya di dalam kelentheng, namun telah mulai dipertunjukkan di luar kelentheng tanpa hambatan. Pada hari raya Imlek, Cap Go Meh dan sebagainya wayang Potehi sudah dipertunjukkan kembali. Para sehu etnis Jawa telah ikut membangun pertunjukan Potehi yang akulturatif.

\section{Kepustakaan}

Brandon, James R. 1993. The Cambridge Guide to Asian Theater. USA : Cambridge University Press.

Eliade, M. dalam Peursen, C.A. van. 1988. Strategi Kebudayaan. Yogyakarta: Kanisius.

Gie, Tio Tiong, (2005). "Empat Narapidana". Majalah Gong No. 67 /VI/2005. Yogyakarta :Yayasan Medis dan Seni Tradisi.

Groenendael, Clara. 1993. "Po-te-hi: The Chinese Glove Puppet Theatre in East Java" dalam Bernard Arps. (Ed). Performance In Java and Bali Studies of Narrative, Theatre, Music, and Dance. London: School of Oriental and African Studies University of London.

Haryono, Timboel, (2004). Seni Pertunjukan Pada Masa Jawa Kuno. Yogyakarta: Pustaka Raja. Mulyono, Sri. 1982. Wayang Asal-usul, Filsafat dan Masa Depannya. Jakarta: Gunung Agung.

\section{Narasumber}

Tok Hok Lay. Lahir: 6 Juli 1969. Ketua Kelenteng Hong San Kiong di Gudo Jombang, Jatim, seorang Maecenas Potehi, pimpinan grup Potehi Hok Ho An/Fu He An di Gudo Jombang. Alamat: Gudo Jombang Jawa Timur. 